\title{
IMPLEMENTING AN INTEGRATED INFORMATION SYSTEM TO SUPPORT DEVELOPMENT PLANNING
}

\author{
MF BHYAT \\ Department of Development, Planning, Environment and Works \\ Guateng Government \\ South Africa
}

\section{INTRODUCTION}

The theme of this seminar is to explore the role that the South African Statistical Association and the Operations Research Society of South Africa can play in the RDP. Not being a professional statistician or an operations researcher it would be presumptuous of me to tell you what role your respective organisations can play. However what I can do is to tell you what we do in the Department of Development, Planning, Environment and Works, how we try to do it, what kinds of questions we pose to ourselves and the kind of data we look at in order to answer some of these questions. From this overview $I$ an sure that you will see where your respective organisations can contribute their specialised skills and research abilities.

2. THE Role of the department of DeVelopment, PlanNing, ENVIRONMENT AND WORKS (DDPE\&W)

The Objective of the DDPE\&W is to foster a development process whereby economic, sectoral, institutional, fiscal and environmental strategies are integrated to provide the optimal allocation of resources between sectors, across the population and across geographical boundaries, all in a manner that will be sustainable, be equitable and of course will empower the traditionally disadvantaged. In order to carry out these objectives the department will 
establish and implement an integrated information system to support development planning and an environmental management system which will ensure that urban, rural and regional development and transformation are achieved efficiently and embody the objective noted above.

All human activity must become sustainable. More sustainable economically, more sustainable environmentally, and more sustainable socially. In order to carry out this mandate we must endeavour to integrate environmental, social and economic considerations into every decision and activity. That is, to fully integrate strategic, cultural and technical aspects into our management system. A hindrance to such an integrated, adaptive and interactive system would be the lack of an institutional environment in which it can operate and be managed. The Directorate of Development Information Systems (DIS) within the DDPE\&W fulfils this institutional role. The DIS is designed as a support system for management to make rational and timely decisions in the development process.

\section{HOW THE DIS IS SET UP, WHO WE INTERACT WITH, WHAT KIND OF DATA ARE WE LOOKING FOR AND WHAT KINDS OF QUESTIONS WE ASK}

The DIS is a key component of an integrated development planning information system. Its mandate is to collect, collate and analyse planning, development and environment information as well as to promote and co-ordinate development and management information systems between departments, different levels of government, the private and community sectors. The kinds of data or information that DIS needs are illustrated by the kinds of question we need to ask, for example:

- Where is it, what does it look like and how does it fit in with overall objectives?

- What are the regional impacts of major development initiatives?

- How to co-ordinate with the plans of other jurisdictions? 
- How to monitor urban/rural development, the question of urban corridors or development corridors vs. greenbelts?

- Infrastructure analysis?

- Bulk services - what is the regional picture, what is the local picture?

- $\quad$ Schools - their location, capacity, accessibility?

- Hospitals; location, capacity, accessibility?

- Transport; private or public, accessibility?

- $\quad$ Roads; their capacity to handle new development?

- The availability of water, contamination of groundwater?

- Soils, geology - engineering aspects.

- Contaminated areas, rehabilitation of abandoned industrial/ mining areas.

- A land registry and property management system for provincially owned assets.

- Illegal settlement - where are they, how many, are they organised? How best to formalise them?

- In terms of services planning, can we assess the impact on surrounding communities, on property values?

- Crime statistics.

The data gathered will be captured and analysed in a Geographical Information System (GIS) which will form the heart of the DIS. Geographical Information Systems are the most important resource and development planning tool to appear in many years. A GIS allows for quick access and analysis of resource information for purposes of decision making. The ability of GIS to integrate spatial data from different sources with different formats, structure, projections or levels of resolution represent a powerful aid to spatially distributed models, particularly those models that integrate more than one variable. The need to integrate environmental information with administrative, political, social and 
economic data in developing development policy represents a powerful incentive for the application of GIS's in environmental and development modelling.

\section{THE ROLE THAT THE SOUTH AFRICAN STATISTICAL ASSOCIATION AND THE OPERATION RESEARCH SOCIETY CAN PLAY}

As you can see information, particularly information related to the numbers of people we have, their ages, where they are, what they do, etc., figure very prominently in the list I have just gone through.

In information systems and specifically Geographic Information Systems, which will be at the heart of our business, the hardware and software constitute only 10 to $15 \%$ of our costs. The balance is acquiring the data and one of our major problems is making sure that the data on which we base our management information system is clean and has integrity, especially in the area of population statistics. The data that are collected, entered, stored, and processed must be sufficiently reliable and error free for the purposes for which they are required.

Although in my introduction I noted that I would not presume to tell you what your role should be, what I would like to outline are some of the problems that we face in acquiring data and assessing the validity of the data. And here I will refer to the headlines in the Engineering News, June 1995, "SA's stats stink". I am sure that most of you are aware of the contents of the article so I don't intend going into all the details but a sample of the comments are revealing: "population figures may be overstated by up to eight million people", "in some instances, particularly on informal sector employment, official statistics provided by government and employers' federation are $50 \%$ out", "it is much quicker to get information about South Africa from the US or UK than it is to try and source accurate information locally. Local figures are sometimes two or three years out of date or simply unavailable". Although this article may have exaggerated the situation, the implications for the RDP especially at the 
Provincial level are very serious. How are we in the DDPE \& $W$ to make informed economic policy development decisions based on erroneous or non existent data? Without reliable information on the local population it is impossible to calculate crime or disease rates. The dismal state of South Africa's statistical system is further illustrated by the fact that to arrive at a demographically reasonable population estimate, the data collected in the 1991 census was adjusted by nearly $18 \%$ (Beth Osborne Daponte, Results from the 1995 Soweto Population Survey: Estimates of the Population of Towns in Soweto, Preliminary Report to the Greater Johannesburg Metropolitan Council, Visiting Experts Program, US State Department). The sample taken by Ms. Depont's study was approximately three times the sample size that was taken for the 1991 census by Central Statistics. In addition her survey from inception to the submission of her report was only seven weeks. Surely we could improve on our collection and analyses methodology?

The examples eited emphasised population and economic data. The same situation exits for example for environmental data. In the earth sciences, the problems of dealing with incomplete or insufficient data have been recognised for some time and statistical or geostatistical solutions have been devised, often with very good results. For example we know that in soil mapping or grade control in mining the carefully drawn boundaries on maps are elegant misrepresentations of changes that are gradual or vague and numerous estimation or interpolation techniques have been devised. Another solution that is being applied is that of fuzzy logic. Is it possible perhaps that this sort of fuzzy logic can be applied to the analyses of demographic data? The obvious solution of collection more information at lower levels does not always solve the problem, because as has been pointed out by proponents of fractals, in natural phenomena collecting more data at increasing levels of detail does nor necessarily remove variability, as it may be an intrinsic aspect of nature that occurs at all scales. 
An area where there is an urgent need for innovative thinking in data collection and analysis is in keeping track of land invasions and squatting. How do we keep track of what is going on. What numbers are involved, where do they come from, what motivates the occupation of a particular area. Is it the proximity to water, electricity, employment, or the mere fact that a piece of ground is vacant? Some of these questions apply also to formalised areas. And it is not merely the logistics of collecting data. Given our history there is a natural fear or reluctance of interviewees to give any valid or meaningful information. Perhaps research ought to be redirected towards methodologies and criteria in which the main thrust for data collection is not directly handled by Government departments but perhaps through some form of citizen participation with direction from researchers such as yourselves.

And lastly the data collection and its format should be oriented towards development needs. 